\title{
Synthesis and characterization of a new methacrylate monomer derived from the cashew nut shell liquid (CNSL) and its effect on dentinal tubular occlusion
}

\author{
Madiana Magalhães Moreira ${ }^{a, b, c}$, Lucas Renan Rocha da Silva ${ }^{b}$, \\ Talita Arrais Daniel Mendes ${ }^{a}$, Sérgio Lima Santiago ${ }^{a}$, \\ Selma Elaine Mazzetto ${ }^{b}$, Diego Lomonaco ${ }^{b}$, Victor Pinheiro Feitosa ${ }^{a, c, *}$ \\ a Postgraduate Program in Dentistry, Federal University of Ceará, Fortaleza, Brazil \\ b Department of Organic and Inorganic Chemistry, Federal University of Ceará, Fortaleza, Brazil \\ c Paulo Picanço School of Dentistry, Fortaleza, Brazil
}

\section{A R T I C L E I N F O}

Article history:

Received 2 February 2018

Received in revised form

11 April 2018

Accepted 30 April 2018

Keywords:

Anacardium occidentale

Cardanol

Organic synthesis

Methacrylates

Epoxy resins

Dentin desensitizing agents

\begin{abstract}
A B S T R A C T
Objective. The aim of this study was to synthesize, to characterize and to evaluate the effects on tubular occlusion of new monomer derived from cashew nut shell liquid (CNSL), also studying the effects of acid challenge (AC) on dentin surfaces treated with desensitizers. Methods. The intermediary cardanol-epoxy (CNE) was synthesized through epoxidation of CNSL, followed by synthesis of cardanol-methacrylate-epoxy (CNME) through methacryloyl chloride esterification. Products were purified through chromatography column and characterized by Fourier transform infrared spectrometry and nuclear magnetic resonance. Resinous dentin desensitizers were formulated containing either unsaturated cardanol (CNU), CNE or CNME. Dentin disks were divided into seven groups: SL - Smear-layer, EDTA — EDTA-treated only, GLUMA - Gluma Desensitizer, OCB - One Coat Bond, CNU - CNU desensitizer, CNE - CNE desensitizer and CNME - CNME desensitizer. Dentinal fluid rate (DFF) was obtained using a Flodec equipment and tubular occlusion employing a scanning electron microscope (SEM), before and after AC. Data of DFF were submitted to two-way ANOVA and Tukey's test $(\mathrm{p}<0.05)$.

Results. GLUMA showed the lower reduction in DFF when compared to the other products, which were statistically similar. Even after AC, CNME presented the most homogenous and occluded surface, while CNE and CNU were partially removed, GLUMA was completely removed and OCB keep an occluded, but irregular surface.

Significance. CNME showed a great reduction of DFF and a homogenous occluded surface, suggesting that it may be a suitable and acid-resistant treatment option for dentine hypersensitivity.
\end{abstract}

@ 2018 The Academy of Dental Materials. Published by Elsevier Inc. All rights reserved.

\footnotetext{
* Corresponding author at: Laboratory PPGO-UFC, Monsenhor Furtado St., Rodolfo Teófilo, Fortaleza, Ceará 60.430-350, Brazil.

E-mail address: victor.feitosa@facpp.edu.br (V.P. Feitosa).

https://doi.org/10.1016/j.dental.2018.04.011

0109-5641/@ 2018 The Academy of Dental Materials. Published by Elsevier Inc. All rights reserved.
} 


\section{Introduction}

Hypersensitive dentin (DH) is a common oral health issue in the adult population, associated with exposed cervical dentin and characterized by short and sharp pain in response to several external stimuli [1,2]. This significant increase in the dentin sensitivity is explained by the most widely accepted "hydrodynamic theory" proposed by Brännström et al. [3]. Such explanation advocates that movements of fluid within the dentinal tubules stimulate pulpal mechanoreceptors, which are interpreted as pain. This clinical condition affects directly the quality of life, thereby motivating the investigations of mechanisms leading to $\mathrm{DH}$ and the development of a wide range of treatment methods to prevent, reduce or eliminate this condition [4].

Several desensitizing agents have been assessed for the treatment of $\mathrm{DH}$, relying on two approaches: nerve desensitization or occlusion of patent dentinal tubules [5]. However, in agreement with the hydrodynamic theory [3], most of the currently employed agents are used to occlude the dentinal tubules, once this strategy may suppress dentinal fluid movement regardless the stimuli evoked, thereby decreasing $\mathrm{DH}$. Although many studies have reported the initial efficacy of these agents, most of them have their therapeutic effects readily arrested or diminished over time due to daily tooth brushing or intermittent consuming of acidic beverages [6].

Gluma Desensitizer (Hereaus Kulzer, Hanau, Germany) is one of the desensitizing agents with the longest history of use in dental clinics. Its mechanism of action relies on precipitation of plasma proteins within dentinal tubules thanks to the high capacity of glutaraldehyde in promoting protein crosslinking. Nevertheless, such compound is highly detrimental to the metabolism of odontoblast-like pulp cells (MDPC-23) [7] and possesses high dissolution capacity in acidic solutions [8], what might cause several cytotoxic issues. Recently, several more biocompatible plant-derived products were investigated in order to replace glutaraldehyde as dentin collagen crosslinking agent [9]. In this regard, new monomers could be created from these plant-derived compounds yielding improved desensitizing agents.

Cashew nut shell liquid (CNSL) emerges as an abundant renewable resource of naturally occurring phenols, also highlighting affinity with dentin collagen and potential to form crosslinking [10]. After the industrial thermal treatment, CNSL is mainly composed by cardanol (approximately 70\%), a long carbon chain phenol (Fig. 1), which grants this compound high hydrophobicity and many reactive sites for organic synthesis [11]. Besides, it does not depict cytotoxic or mutagenic effects [12]. Advances in the development of long-lasting dentin sealing technologies should achieve acid-resistant desensitizing agents. Therefore, the synthesis of a methacrylate epoxy cardanol monomer could obtain biocompatible, hydrophobic and acid-resistant agent, once the oxirane ring can open in acid environments $[13,14]$ and act as a latent polymerization improving the material over time.

The aim of this manuscript was to synthesize, to characterize and to evaluate the effects on dentin desensitization (tubular occlusion) of new methacrylate monomer derived from the CNSL, also studying the effects of acid chal-

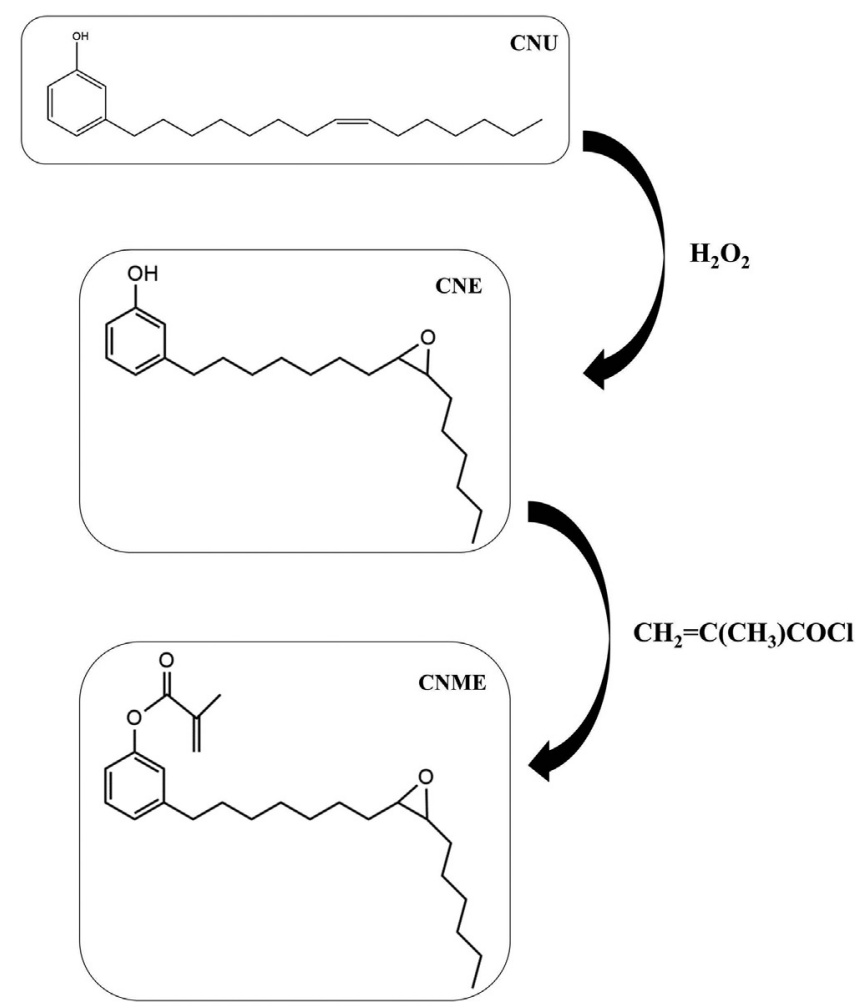

Fig. 1 - Synthetic route: unsaturated cardanol (CNU) was epoxidized with hydrogen peroxide, using formic acid as a catalyst, in order to incorporate an oxirane ring where the unsaturation was located and form cardanol-epoxy (CNE). CNE was esterified with methacryloyl chloride, in the presence of triethylamine as a catalyst, to incorporate one methacrylate functionality where the hydroxyl was located and to obtain the final monomer cardanol-methacrylate-epoxy (CNME).

lenge on dentin surfaces treated with desensitizers. The study hypotheses under investigation were that (1) there are differences in the dentinal tubule occlusion among the desensitizing agents, and (2) the new monomer can promote acid resistance.

\section{Materials and methods}

\subsection{Reagents}

CNSL (technical grade) was kindly supplied by Amêndoas do Brasil LTDA (Fortaleza, Brazil). Formic acid, hydrogen peroxide, triethylamine, 3,5-Di-tert-4-butylhydroxytoluene (BHT), methacryloyl chloride, anhydrous sodium sulfate and solvents were purchased from Sigma-Aldrich (St. Louis, USA) and used as received. Silica gel (Merck) was employed in the chromatographic separations.

\subsection{Synthesis of cardanol-epoxy (CNE)}

Briefly, thecardanol-epoxy (CNE) synthesis was accomplished with epoxidation reaction of unsaturations of the CNSL, using hydrogen peroxide and formic acid with a molar ratio of 1:3:1, 
respectively. First, CNSL was placed in a round bottom flask and then formic acid was added, followed by the slow addition of hydrogen peroxide under magnetic stirring at room temperature $\left(25^{\circ} \mathrm{C}\right)$. The resulting solution was vigorously stirred at $65^{\circ} \mathrm{C}$ for $2 \mathrm{~h}$ and $30 \mathrm{~min}$ and monitored by thin layer chromatography. Next, the product was isolated by solvent extraction from the aqueous solution and the organic phase was dried using anhydrous sodium sulfate. Finally, the product was filtered followed by the evaporation of the solvent in a rotary evaporator, and the crude product was passed through a silica chromatography column to afford the purified CNE monomer (Fig. 1).

\subsection{Synthesis of cardanol-methacrylate-epoxy (CNME)}

In a generic way, cardanol-methacrylate-epoxy (CNME) synthesis was accomplished with an esterification reaction of the aromatic hydroxyl of CNE, using triethylamine and methacryloyl chloride with the molar ratio of 1:1:1, respectively. Overall, CNE was placed into a round bottom flask and dissolved in toluene at room temperature $\left(25^{\circ} \mathrm{C}\right)$ under vigorous stirring. Triethylamine was added as catalyst to the mixture, followed by BHT, as polymerization inhibitor. Thereafter, methacryloyl chloride was slowly added and the slurry was stirred at $60^{\circ} \mathrm{C}$ for $4 \mathrm{~h}$, being monitored by thin layer chromatography. Then, the product was isolated by simple solvent extraction from the aqueous solution and the organic phase was dried using anhydrous sodium sulfate. Finally, the product was filtered followed by the evaporation of the solvent in a rotary evaporator, and the crude product was passed through a silica chromatography column to afford the purified CNME monomer (Fig. 1). Due to the presence of the methacrylate group, the product was kept in a fridge $\left(4^{\circ} \mathrm{C}\right)$ and protected by aluminum foil after the addition of BHT to avoid spontaneous polymerization.

\subsection{Fourier transform infrared spectroscopy (FTIR)}

Samples of the synthesized and isolated products were characterized by a Fourier transform infrared spectrophotometer (Spectrum Frontier, Perkin-Elmer Corp., Norwalk, USA) equipped with a crystal to perform attenuated total reflectance (ATR-FTIR) analysis. Samples were individually dispensed onto the crystal and spectra were obtained in a spectral range of $4000-550 \mathrm{~cm}^{-1}$ with $4 \mathrm{~cm}^{-1}$ resolution in transmittance mode. FTIR spectra were obtained in triplicate for each product, using the unsaturated cardanol as reference, and then processed for baseline correction and normalization.

\subsection{Nuclear magnetic resonance (NMR)}

The nuclear magnetic resonance (NMR) spectra of carbon and hydrogen were obtained in a Brucker spectrometer instrument, model DPX 300 (Rheinstetten, Germany) operating at $75 \mathrm{MHz}$ for NMR $13 \mathrm{C}$ and $300 \mathrm{MHz}$ for NMR $1 \mathrm{H}$. Deuterated chloroform was used as a solvent at room temperature.

\subsection{Resin-based dentin desensitizer formulation}

A resinous dentin desensitizer was formulated containing $20 \mathrm{wt} \%$ CNME, $50 \mathrm{wt} \%$ triethyleneglycoldimethacrylate
(TEGDMA), $28.5 \mathrm{wt} \%$ urethane dimethacrylate (UDMA), $0.5 \mathrm{wt} \%$ camphorquinone (CQ) and $1 \mathrm{wt} \%$ ethyl-4dimethylamine benzoate (EDAB). Similar resin-based desensitizers were also formulated with $20 \mathrm{wt} \%$ of unsaturated cardanol (CNU) or $20 \mathrm{wt} \% \mathrm{CNE}$ instead of CNME. As commercial controls, Gluma Desensitizer (Heraeus Kulzer, Hanau, Germany) was used, which is based on glutaraldehyde and hydroxyethyl methacrylate (HEMA), and One Coat Bond SL (Coltène/Whaledent Inc., Mahwah, USA) was employed as resin-based adhesive for desensitization.

\subsection{Preparation of specimens}

Forty nine extracted sound human third molars were used after approval by the Research Ethics Committee of Federal University of Ceará (protocol 1482602). They were stored in $0.1 \%$ thymol solution at $4{ }^{\circ} \mathrm{C}$ for no longer than one month. Occlusal enamel and roots were removed using a slow-speed water-cooled diamond saw (Isomet 4000; Buehler, Lake Bluff, USA) in order to obtain a disk $(0.9 \pm 0.2 \mathrm{~mm}$ in thickness) from middle coronal dentin from each tooth as described by Sauro et al. [15]. These specimens were wet-abraded using a 600-grit silicon carbide paper (30 s) to create a standard smear layer, that was subsequently removed using 17\% EDTA ( $\mathrm{pH}$ 7.4) for 2 minutes followed by an ultrasonic bath containing distilled water for $5 \mathrm{~min}$. The dentin disks were randomly divided into the groups $(n=7)$. Group SL comprised the reference specimens, which were untreated with retained smear-layer. Group EDTA comprised control EDTA-treated specimens with opened dentin tubules (100\% permeability) and that no desensitizing treatment was applied. Specimens in further groups were stored individually with moist paper to keep them hydrated. They were hydrated in distilled water for $30 \mathrm{~min}$ [16] before treatment as follows: group GLUMA was treated with Gluma Desensitizer; group OCB was treated with One Coat Bond SL; group $\mathrm{CNU}$ was treated with the resin-based desensitizer containing unsaturated cardanol; group CNE was treated with the resinbased desensitizer containing cardanol-epoxy and group CNME was treated with the resin-based desensitizer containing cardanol-methacrylate-epoxy. After treatment and initial investigation, two specimens of each group were exposed to acid challenge with $6 \%$ citric acid for further evaluation [15].

\subsection{Dentin desensitizing treatment}

GLUMA and OCB were applied according to manufacturer's instructions as described in Table 1. Specimens treated with CNSL compounds were pretreated with absolute ethanol for 30 s and the experimental resin-based desensitizers with CNU, CNE or CNME were applied with microbrush for $20 \mathrm{~s}$, gently air-dried, applied again for $20 \mathrm{~s}$ and light-cured for $40 \mathrm{~s}$ using the LEDBiolux (Bio Art, São Carlos, São Paulo, Brazil). Afterwards, specimens of each group were immersed individually for $1 \mathrm{~min}$ in a 12 -well plate, with $6 \%$ citric acid. After the immersion, they were thoroughly rinsed with deionized water. 
Table 1 - Commercial desensitizing agents and application procedures.

\begin{tabular}{|c|c|c|c|}
\hline Desensitizing agent & Components & Procedure & Manufacturer \\
\hline $\begin{array}{l}\text { Gluma Desensitizer } \\
\text { (GLUMA) }\end{array}$ & $\begin{array}{l}\text { Aqueous solution containing } 5 \% \\
\text { glutaraldehyde and } 35 \% \text { HEMA }\end{array}$ & Apply and leave for $60 \mathrm{~s}$, dry, rinse & Hereaus Kulzer, Hanau, Germany \\
\hline One Coat Bond SL (OCB) & $\begin{array}{l}\text { Methacrylate }{ }^{\mathrm{a}} \text {, polyalkenoat } \\
\text { methacryliert }^{\mathrm{a}} \text {, } \text { water }^{\mathrm{a}}\end{array}$ & $\begin{array}{l}\text { Apply (dwell for } 20 \mathrm{~s}) \text {, gentle air, } \\
\text { light-cure }{ }^{b}(30 \mathrm{~s})\end{array}$ & $\begin{array}{l}\text { Coltène/Whaledent Inc., Mahwah, } \\
\text { USA }\end{array}$ \\
\hline \multicolumn{4}{|c|}{$\begin{array}{l}\text { HEMA: 2-hyroxyethyl methacrylate. } \\
\text { a Not provided by the manufacturer. } \\
\text { b LED Biolux (BioArt, São Carlos, São Paulo, Brazil). }\end{array}$} \\
\hline
\end{tabular}

\subsection{Dentine permeability evaluation}

The rate of fluid flow was obtained using Flodec equipment (Flodec-System, Demarco Engineering, Switzerland) by recording measurements of hydraulic conductance (Lp). Specimens were attached to a plexiglass plate, penetrated with a stainless steel tube, with an exposed standard dentin surface, which were individually connected to the hydraulic pressure device. Fluid passed under a constant deionized water pressure of $15 \mathrm{~cm} \mathrm{H}_{2} \mathrm{O}(1.47 \mathrm{kPa})$. The movement of an air bubble inside a capillary tube in the hydraulic system was recorded during $5 \mathrm{~min}$; the last $3 \mathrm{~min}$ records were used to obtain the Lp for each experimental condition [17].

After the immersion of all specimens into the EDTA solution, the initial Lp of each specimen was calculated, which were submitted to statistical analysis. Following, the dentin disks were grouped into the experimental groups $(n=3)$ in order to obtain normal data $(p>0.05)$ and no statistical difference among baseline permeability values.Subsequently, the specimens were wet-abraded on the occlusal side with 600grit $\mathrm{SiC}$ paper for $30 \mathrm{~s}$ to create standardized smear layer, then Lp was measured to evaluate the minimum permeability.To obtain the maximum permeability (Lp $\max =100 \%$ was arbitrarily assigned), that allows an evaluation of the changes in dentin permeability after the application of treatments, all specimens were etched for $15 \mathrm{~s}$ with $37 \%$ phosphoric acid solution, followed by rinsing with deionized water.

Moreover, the application of experimental materials on the dentin specimens was carried out as aforementioned. After treatments, hydraulic conductance was measured again and treatment permeability was expressed as a percentage (Lp \%) of the maximum Lp value (100\%). Finally, each treated dentin disk was immersed in $6 \%$ citric acid solution for $60 \mathrm{~s}$ in order to evaluate the acid resistance of desensitizing treatments and the last Lp was performed after washing the acid. The means (\% reduction) and standard deviations for each group were calculated and the statistical analysis was performed with two-way ANOVA and Tukey's test $(p<0.05)$.

\subsection{Scanning electron microscopy (SEM)}

Four specimens per group were analyzed by scanning electron microscopy (SEM). They were prepared as cited in Subsections 2.7 and 2.8 and used two specimens after tretament and two after acid challenge. Specimens were dehydrated in silica gel, mounted on stubs, gold-sputter coated and observed in SEM (Inspect S50, FEI Company, Amsterdam, Netherlands) operated at $20 \mathrm{kV}$. Representative scanning electron micrographs were taken at different magnifications and were chosen by two evaluators based on the frequently observed appearance of the dentin surface.

\section{Results \\ 3.1. Characterization of CNU, CNE and CNME}

Fig. 2 illustrates the infrared spectra (FTIR) of CNU, CNE and CNME. The stretch of the $\mathrm{C}-\mathrm{O}-\mathrm{C}$ (oxirane ring) bond at $826 \mathrm{~cm}^{-1}$ is presented in CNE and CNME spectra. The characteristic signal of the vibrational stretch of the $\mathrm{O}-\mathrm{H}$ bond of phenolic rings present in the spectra of CNU and CNE at $3388 \mathrm{~cm}^{-1}$, disappeared in CNME, indicating the substitution of this group. Absorptions bands at $1740 \mathrm{~cm}^{-1}$ and $1238 \mathrm{~cm}^{-1}$ are referred to the bonds $\mathrm{C}=\mathrm{O}$ and $\mathrm{C}-\mathrm{CO}-\mathrm{O}$, respectively, are due the presence of the methacrylic group of CNME.

The $1 \mathrm{H}$ and 13C NMR spectra of the reactant (CNU) and products (CNE and CNME) are displayed in Fig. 3. In the $1 \mathrm{H}$ NMR spectra (Fig. 3a) were observed common signals for all these compounds in the regions between 0.8 to $1.7 \mathrm{ppm}$ and 6.5 to $7.5 \mathrm{ppm}$, attributed to the aliphatic hydrogens form the side chain and the aromatic ring hydrogens, respectively. The respective carbon atoms attached to these hydrogens were observed in the 13C NMR spectra (Fig. 3b), where signals from 10 to $40 \mathrm{ppm}$ were attributed to aliphatic carbon atoms of the side-chain, while the signals between 110-160 ppm were originated from both the aromatic ring as also from the unsaturated carbons form the methacrylic group. Specific changes were observed in the spectra of CNE and CNME when compared to the starting material (CNU). Signals at $\delta$ 2.75-3.00, atributed to the oxirane ring of CNE and CNME (Fig. 3a, 3), was confirmed by the signal at the range of $55-60$ ppm in the $13 \mathrm{C}$ NMR (Fig. 3b, 5). The successful esterification of the aromatic hydroxyl was confirmed by the signals at $\delta 5.5-6.5$, referred to the vinylic hydrogens (Fig. 3a, 1) of CNME, and the sharp sig$\mathrm{nal}$ at $2.2 \mathrm{ppm}$ (Fig. 3a, 4), attributed to the terminal methyl group. In the $13 \mathrm{C}$ NMR spectra, was also observed a signal at $166 \mathrm{ppm}$, characteristic of the carbonylic carbon (Fig. 3b, 4) of the methacrylic group.

\subsection{Dentin permeability evaluation}

The results of percentage reduction in dentinal fluid flow achieved by the desensitizing agents when compared to the baseline flow rate are illustrated in Fig. 4. CNME showed the highest reduction in flow rate after treatment (87.1\%). The application of OCB, CNU, CNE and CNME onto the dentin disks reduced dentine permeability with no statistical difference 


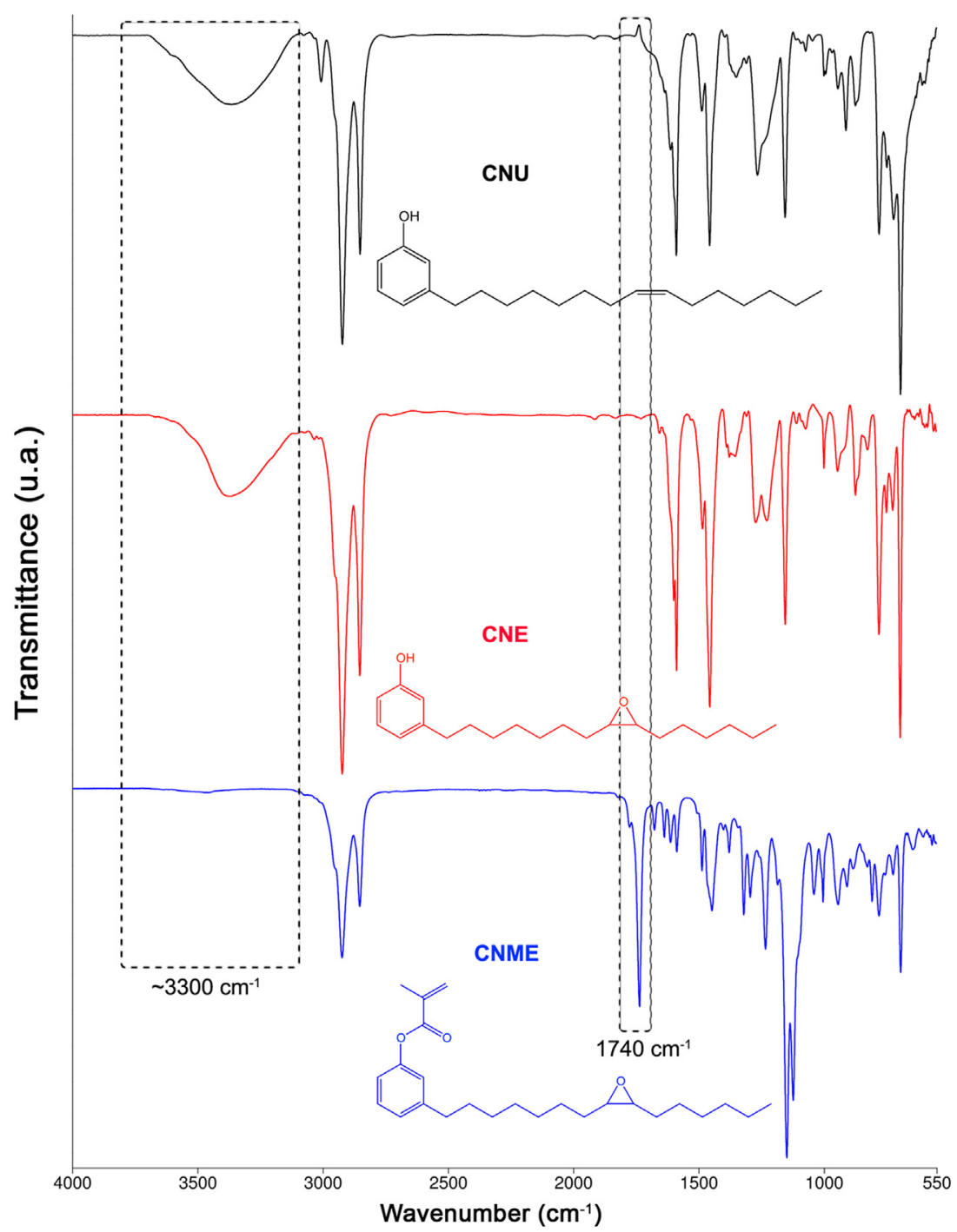

Fig. 2 - FTIR spectra obtained from the monomers unsaturated cardanol (CNU - top spectrum), cardanol-epoxy (CNE middle spectrum) and cardanol-methacrylate-epoxy (CNME - bottom spectrum). The stretch of the $\mathrm{C}-\mathrm{H} \mathrm{sp}^{2}$ (aliphatic) bond at $3009 \mathrm{~cm}^{-1}$, is only observed in CNU. The stretch of the C-O-C (oxirane ring) bond at $826 \mathrm{~cm}^{-1}$ is presented in CNE and CNME spectra (first dotted line in the right), demonstrating the successful epoxidation. The spectra of CNU and CNE shows the absorption band at $3388 \mathrm{~cm}^{-1}$, characteristic of vibrational stretch of the $\mathrm{O}-\mathrm{H}$ bond of the phenol, that has disappeared in CNME. The absorptions bands at $1740 \mathrm{~cm}^{-1}$ and at $1238 \mathrm{~cm}^{-1}$ referring to the bonds $\mathrm{C}=0$ (carbonyl from methacrylate) and C-CO-O, respectively, occurred only in CNME.

between them, whilst GLUMA induced the lowest reduction of the dentinal flow $(p<0.05)$. There was no statistical difference between before and after acid challenge within each desensitizing treatment.

\subsection{SEM evaluation of the occlusion of dentinal} tubules

Characteristic SEM images of the dentin surfaces on which the desensitizing materials were applied are shown in Fig. 5. Different changes of the morphologies of the dentin surfaces were observed according to the groups. GLUMA presented partially occluded tubules (Fig. 5c), which were virtually all exposed after acid challenge (Fig. 5d). OCB showed occluded surface with some water droplets (Fig. 5e), and some porosities after citric acid (Fig. 5f). CNU and CNE presented occluded dentin tubules after treatment (Fig. $5 \mathrm{~g}$ and i, respectively), but they were partially removed after acid, showing some patent tubules (Fig. $5 \mathrm{~h}$ and j, respectively). CNME produced an homogenous and occluded surface (Fig. 5k), even after acid challenge (Fig. 51).

\section{Discussion}

The present study evaluated the effectiveness of dentinal tubule occlusion among desensitizing agents, which depicted different degrees of occlusion. Therefore, hypothesis (1) needs to be accepted. Besides, the acid resistance of these agents 

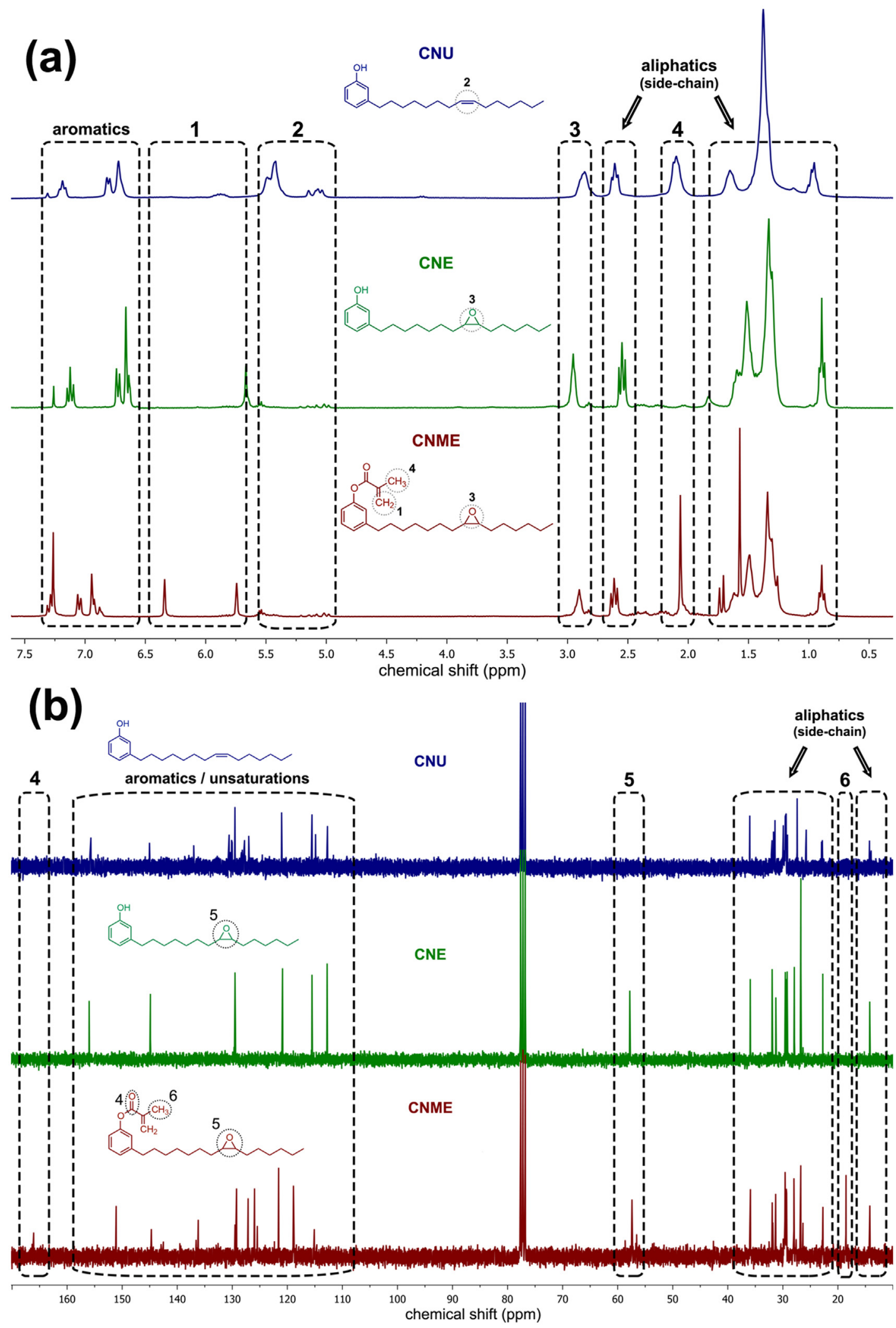

Fig. 3 - ${ }^{1} \mathrm{H}$ NMR (a) and ${ }^{13} \mathrm{C}$ NMR (b) spectra of the monomers cardanol unsaturated (CNU - top spectrum), cardanol-epoxy (CNE - middle spectrum) and cardanol-methacrylate-epoxy (CNME - bottom spectrum). CNU showed a signal at the range of $\delta$ 5-6 (Fig. 3a - dotted rectangle 2) relative to the olefinics hydrogens of the lateral chain, that was absent in CNE and CNME. The signal at the range of $\delta$ 2.75-3 (Fig. 3a - dotted rectangle 3) is attributed to the oxirane ring of CNE and CNME, which was confirmed by the signal at the range of 55-60 ppm in ${ }^{13} \mathrm{C}$ NMR (Fig. 3b - dotted rectangle 5). Between $\delta 5.5-6.5$ (Fig. 3a - dotted rectangle 1) the signals referring to the vinylic hydrogens of methacrylate group of CNME may be observed. 


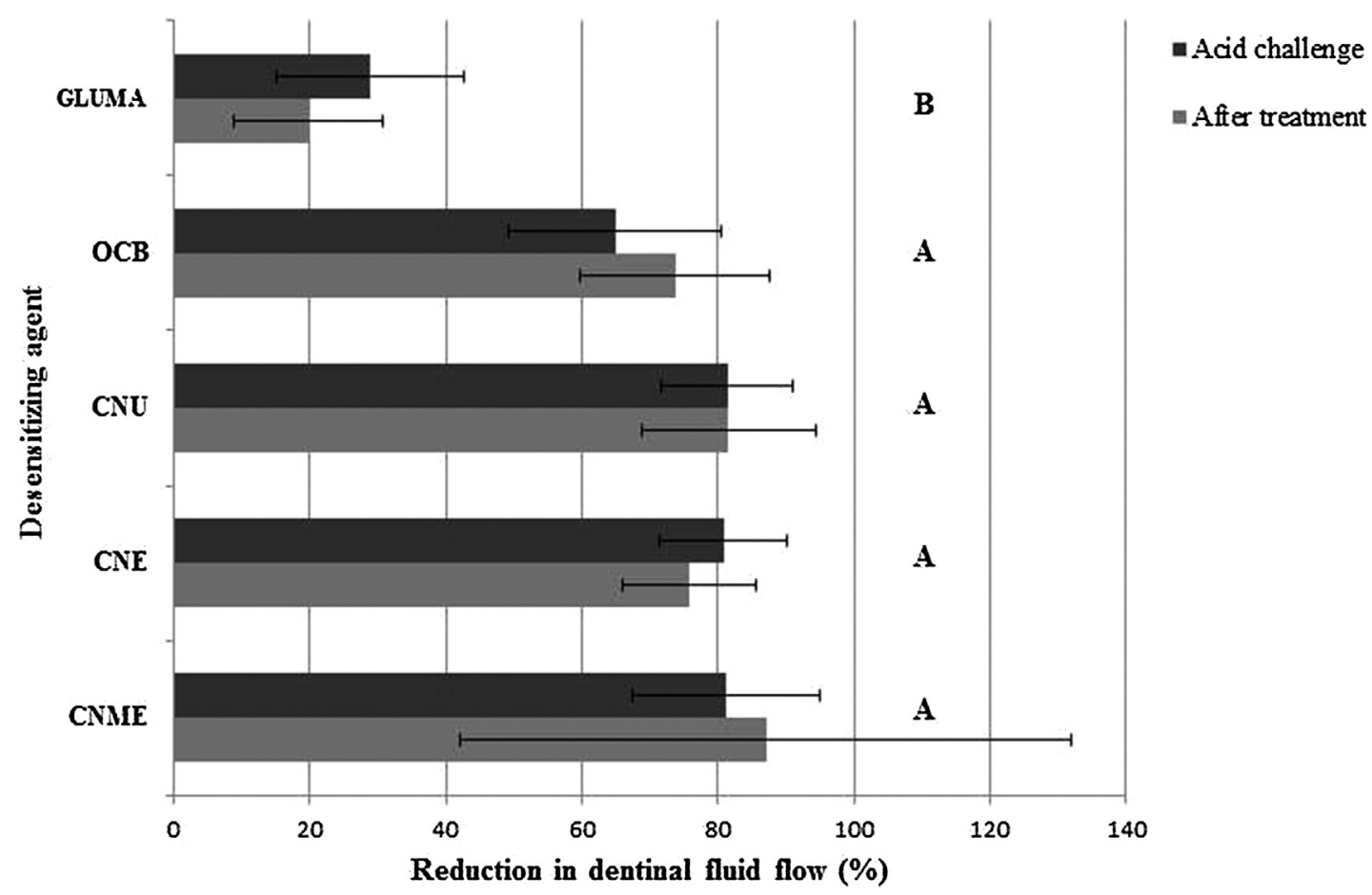

Fig. 4 - Means and standard deviations of the reduction in dentinal fluid flow (\%) values after treatment and after acid challenge. Different capital letters indicate significant differences between the five desensitizing agents ( $p<0.05)$. No statistical difference was found after treatment and after acid challenge within each desensitizer $(p>0.05)$. Numerically, CNME showed the highest reduction in dentinal flow rate after treatment (87.1\%). GLUMA induced the lowest reduction of the dentinal flow when compared to further products $(p<0.05)$, which were statistically similar. GLUMA - Gluma Desensitizer, OCB - One Coat Bond SL, CNU - unsaturated cardanol, CNE - cardanol-epoxy, CNME cardanol-methacrylate-epoxy.

was evaluated, which fully accomplished only by the new monomer. Consequently, the hypothesis (2) also requires acceptance.

The CNME monomer was synthesized via a two-step procedure (Fig. 1). In the first step, the intermediary CNE was successfully achieved, by means of an adaptation of a previously published protocol [18]. The second step was the esterification of the phenolic hydroxyl in CNE with methacryloyl chloride, in order to afford the final desired CNME in high yields ( $>75 \%)$. The monomers were isolated and characterized by FTIR, ${ }^{1} \mathrm{H}$ and ${ }^{13} \mathrm{C}$ NMR. All spectra clearly show the functionalization of unsaturation with an oxirane ring (CNE and CNME) and of the phenol moiety with a methacrylate pendant (CNME) (Figs. 2 and 3). By the author's knowledge, this twostep reaction to synthesize dental monomers has not been reported in the literature so far. Furthermore, this is the first study investigating a dental monomer synthesized from CNSL compounds.

The influence of desensitizing agents on dentin permeability was tested with a Flodec computerized device. After introducing an air bubble in the system, the linear displacement of the bubble within the glass capillary was measured. This movement occurs by water pressure through the discs at simulated pulpal pressure, once only a low, physiological pressure is suggested to be suitable for measuring hydraulic conductance in dentin [19]. This information was transmitted by microflow sensors to a computer connected to the equipment, which converts by software this displacement to rate of fluid flow.

GLUMA revealed significant lower reduction of the dentinal flow when compared to the further agents (Fig. 4). This result was also found in other study [20], which found that photocurable resin desensitizers (Seal \& Protect; Dentsply Caulk, Milford, DE, USA) demonstrates greater reduction on permeability than Gluma Desensitizer. The investigation of Camps et al. [21] may provide an explanation for this result, as they found that when tubules were filled with phosphate-buffered saline (PBS), it was observed an decrease in hydraulic conductance in dentin disks treated with Gluma desensitizing agent. Contrariwise, other study [22], even using PBS, revealed the same amount of reduction in permeability by Gluma and Seal \& Protect, but they showed the highest hydraulic conductance (less than $40 \%$ of permeability reduction) among the tested agents. The present study did not usePBS or simulated body fluid. Therefore, the mechanism of precipitation of proteins by glutaraldehyde may have been negatively affected by the use of deionized water. Yet, it is important to remember that besides plasma proteins, there are many other sources of

The ${ }^{3} \mathrm{C}$ NMR confirmed the presence of the methacrylate group showing the signal at the range of $160-170 \mathrm{ppm}$ (Fig. $3 \mathrm{~b}-\mathrm{dotted}$ rectangle 4 ), characteristic of the carbonyl $(\mathrm{C}-\mathrm{O})$. 


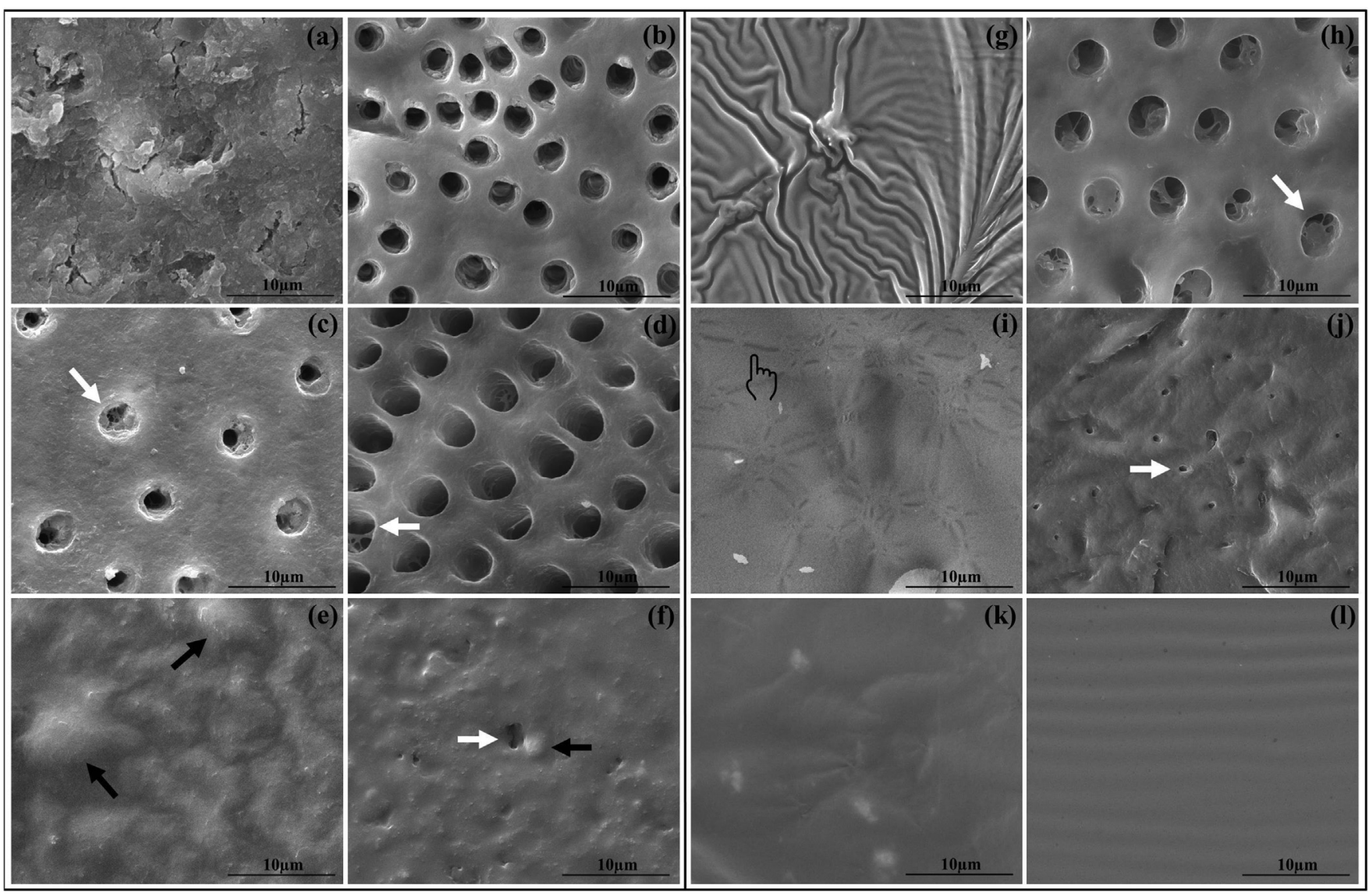

Fig. 5 - SEM micrographs depicting the most common features of dentin surfaces after treatment and after acid challenge with $6 \%$ citric acid. White arrows indicate partially occluded dentinal tubules, while black arrows are designated for water droplets. The pointer is indicating phase separation. The different groups are divided as follows: (a) retained smear-layer, (b) EDTA-treated only, with opened dentin tubules, (c) dentin surface treated with Gluma Desensitizer (GLUMA), (d)

GLUMA-treated dentin after acid challenge, (e) surface treated with One Coat Bond SL (OCB), (f) OCB-treated dentin after acid, (g) dentin surface treated with desensitizer containing unsaturated cardanol (CNU), (h) CNU-treated specimens after acid, (i) surface treated with desensitizer containing cardanol-epoxy (CNE), (j) CNE-treated specimens after acid, (k) surface treated with desensitizer containing cardanol-methacrylate-epoxy (CNME) and (1) CNME-treated specimens after acid. SEM demonstrated that initially GLUMA only partially occluded the tubules (c) but showed almost complete dentin exposure after acid challenge (d). OCB created an occluded surface, but irregular due to a great amount of water droplets (observed in e and $\mathrm{f}$ ). Besides, an initial degradation and exposure of tubules were noted (f). CNU covered the dentin surface with a frilled film thanks to its incomplete polymerization (g), the reason why it was partially removed after acid (h). CNE showed phase separation on occluded surface (pointer in i), which facilitated the opening of tubules entrance after acid (j). CNME achieved a complete obliteration of the dentinal tubules, even after acid challenge, presenting a homogenous film (k, l).

proteins such as collagen and non-collagenous proteins from dentin. Nevertheless, the use of PBS or simulated body fluid as a dentinal tubular fluid could result in sedimentation in the glass capillary what would impair consistency of the results. This is the reason why deionized water was chosen for this study.

The SEM images after the application of GLUMA (Fig. 5c) revealed only minor occlusion of tubules demonstrated by the decrease in tubule diameter, which became wide-open after acid exposure (Fig. 5d). GLUMA possesses low acid dissolution resistance [8], which may be explained by its hydrophilic components that can be easily removed or degraded in acidic environment. It is proposed that during the reaction between amino group-containing substances in dentin and glutaralde- hyde, the polymerization of HEMA take place and start the formation of a HEMA polymer [23]. Nevertheless, the leachability of HEMA is well-known due to its small molecular weight and hydrophilicity, which indeed may contribute to higher dissolution in acid solutions. Clinically this implicates in many returns of patients to re-apply the desensitizing agent, thereby increasing the costs and reducing the satisfaction with treatment.

The further desensitizers obtained statistically similar reduction on dentinal fluid flow. However, CNME monomer achieved a numerically higher reduction on permeability than the others, especially when compared to OCB, which presented an intermediary reduction (Fig. 4). OCB is a water-based two-step etch-and-rinse adhesive chosen for this study due 
to great bonding performance and resistance to thermocycling degradation [24]. Moreover, OCB contains HEMA in its composition (similar to GLUMA) and water as a solvent, thus, it is interesting to investigate the resistance of a relatively hydrophilic adhesive to acid challenge. The presence of these hydrophilic compounds may lead to higher permeability due to leaching of HEMA or even a hydrolytic degradation of the polymer [25]. On the other hand, CNME is a hydrophobic monomer that can create a regular layer thereby preventing these types of degradation.

The survey of Brunton et al. [8] revealed a level of acid resistance of OCB. On the other hand, in this study OCB exhibited great amount of water droplets before and after acid challenge (Fig. 5e and f) on SEM, also depicting signs of adhesive layer degradation (Fig. 5f). The water permeability of simplified hydrophilic dental adhesives resembles permeable membranes, which allows higher fluid diffusion [26]. Indeed, in a clinical point of view, the longevity of desensitizing treatment may be jeopardized by such imperfections [27].

The desensitizing containing unsaturated cardanol depicted a corrugated layer (Fig. 5g) due to an incomplete polymerization. It is expected that only methacrylate monomers have been light-cured and unsaturated cardanol remained unchanged within the polymer formed. The effective antioxidant role of phenols of the CNSL has been evidenced [28] and may play a role on such incomplete polymerization of desensitizer. This defective and superficial layer was removed after acid, although some tubules remained partially occluded (Fig. 5h). The desensitizing containing the intermediary CNE exhibited a layer with clear phase separation (Fig. 5i). This could be due to the presence of the hydroxyl functionality of cardanol-epoxy pendant to aromatic ring that can act as a hydrophilic site permeating the hydrophobic UDMA-polymer. After acid challenge, the entrance of the tubules was also exposed, most likely caused by hydrolytic degradation of CNE (Fig. 5j), which does not participate on methacrylate co-polymerization due to the absence of such polymerizable functionality. Nevertheless, CNE showed higher occlusion after acid than CNU, thanks likely to an increase of crosslinking obtained by the acid-catalyzed hydrolysis of epoxides $[13,14]$.

CNU and CNE showed a great reduction of permeability, even after acid challenge, which seems contradictory with the SEM results. This discrepancy between dentinal fluid flow and SEM observations might be explained because SEM observation is able to assess only superficial characteristics whilst dentinal fluid flow might be affected by internal tubular occlusion. Kolker et al. also demonstrated that there is not a correlation between these two experiments [22].

The desensitizing containing the final monomer CNME attained uniform and occluded layer before and after acid (Fig. 5k and l). CNME methacrylate functionality ensured the regular photo-polymerization and formation of a homogenous polymer. Furthermore, methacrylate removed the hydrophilic hydroxyl and, consequently, generated a more hydrophobic monomer. This hydrophobicity yields a polymer with lower wettability, water sorption, water droplets and hydrolytic degradation than the hydrophilic ones [25]. Also, the opening of the oxirane ring in acid environment and the resulting increased crosslinking might create a smart material [29], which becomes more resistant in contact with many different acids from the diet of patients over the years.

CNME monomer was synthesized through a simplified procedure and emerges as a potential dental monomer that can add value to a natural by-product from the cashew nut industrial processing, which is produced in large scale $(1,000,000$ tonnes in 2013) [11]. Besides, it is a HEMA-free desensitizer, which might be a safer option to reduce dentin sensitivity [7]. Furthermore, CNME confirmed that its hydrophobicity and acid-resistance developed a potential long-lasting desensitizing agent, improving the material over time.

\section{Conclusion}

CNME showed a significant reduction of dentin permeability and a uniform occluded surface even after acid exposure, suggesting that it may be a suitable acid-resistant treatment option for dentin hypersensitivity.

\section{Acknowledgments}

This research was supported by CNPq-Brazil (grant 457931/2014-0) and Capes (grant 23038.006958/2014-96) (PI VPF).

\section{REFERENCES}

[1] Addy M, Dowell P. Dentine hypersensitivity—a review. J Clin Periodontol 1983;10(4):351-63.

[2] Cartwright RB. Dentinal hypersensitivity: a narrative review. Community Dent Health 2014;31(1):15-20.

[3] Brännström M, Lindén LÅ, Åström A. The hydrodynamics of the dental tubule and of pulp fluid. A discussion of its significance in relation to dentinal sensitivity. Caries Res 1967;1(4):310-7.

[4] Mantzourani M, Sharma D. Dentine sensitivity: past, present and future. J Dent 2013;41(Suppl. 4):S3-17.

[5] Tian L, Peng C, Shi Y, Guo X, Zhong B, Qi J, et al. Effect of mesoporous silica nanoparticles on dentinal tubule occlusion: an in vitro study using SEM and image analysis. Dent Mater J 2014;33(1):125-32.

[6] Lee BS, Tsai HY, Tsai YL, Lan WH, Lin CP. In vitro study of DP-bioglass paste for treatment of dentin hypersensitivity Dent Mater J 2005;24(4):562-9.

[7] Scheffel DLS, Soares DG, Basso FG, de Souza Costa CA, Pashley DH, Hebling J. Transdentinal cytotoxicity of glutaraldehyde on odontoblast-like cells. J Dent 2015;43(8):997-1006.

[8] Brunton PA, Kalsi KS, Watts DC, Wilson NHF. Resistance of two dentin-bonding agents and a dentin desensitizer to acid erosion in vitro. Dent Mater 2000;16(5):351-5.

[9] Bedran-Russo AK, Pauli GF, Chen SN, McAlpine J, Castellan CS, Phansalkar RS, et al. Dentin biomodification: strategies, renewable resources and clinical applications. Dent Mater 2014;30(1):62-76.

[10] Moreira MA, Souza NO, Sousa RS, Freitas DQ Lemos MV, De Paula DM, et al. Efficacy of new natural biomodification agents from Anacardiaceae extracts on dentin collagen cross-linking. Dent Mater 2017;33(10):1103-9.

[11] Lomonaco D, Mele G, Mazzetto SE. Cashew nutshell liquid (CNSL): from an agro-industrial waste to a sustainable 
alternative to petrochemical resources. In: Anilkumar P, editor. Cashew nut shell liquid: a gold field for functional materials. 1st ed. Springer International Publishing; 2017. p. 19-38.

[12] Leite AS, Dantas AF, Oliveira GLS, Gomes Júnior AL, de Lima SG, Citó AMGL, et al. Biomed Res Int 2015;2015:1-16.

[13] Muniz Filho RCD, Alves de Sousa SA, Pereira FS, Ferreira MMC. Theoretical study of acid-catalyzed hydrolysis of epoxides. J Phys Chem A 2010;114(15):5187-94.

[14] Salimon J, Abdullah BM, Yusop RM, Salih N, Yousif E. Synthesis and optimization ring opening of monoepoxide linoleic acid using p-Toluenesulfonic acid. Springerplus 2013;2(1):429.

[15] Sauro S, Lin CY, Bikker FJ, Cama G, Dubruel P, Soria JM, et al. Di-calcium phosphate and phytosphingosine as an innovative acid-resistant treatment to occlude dentine tubules. Caries Res 2016;50(3):303-9.

[16] Eliades G, Mantzourani M, Labella R, Mutti B, Sharma D. Interactions of dentine desensitisers with human dentine: morphology and composition. J Dent 2013;41(Suppl. 4):S28-39.

[17] Calabria M, Porfirio R, Fernandes S, Wang L, Buzalaf M, Pereira JC, et al. Comparative in vitro effect of TiF4 to NaF and potassium oxalate on reduction of dentin hydraulic conductance. Oper Dent 2014;39(4):427-32.

[18] Suresh KI. Rigid polyurethane foams from cardanol: synthesis, structural characterization, and evaluation of polyol and foam properties. ACS Sustain Chem Eng 2012;1(2):232-42.

[19] Ishihata H, Kanehira M, Finger WJ, Takahashi H, Tomita M, Sasaki K. Effect of two desensitizing agents on dentin permeability in vitro. J Appl Oral Sci 2017;25(1):34-41.

[20] Kim SY, Kim EJ, Kim DS, Lee IB. The evaluation of dentinal tubule occlusion by desensitizing agents: a real-time measurement of dentinal fluid flow rate and scanning electron microscopy. Oper Dent 2013;38(4):419-28.

[21] Camps J, Pizant S, Dejou J, Franquin JC. Effects of desensitizing agents on human dentin permeability. Am J Dent 1998;11(6):286-90.

[22] Kolker JL, Vargas MA, Armstrong SR, Dawson DV. Effect of desensitizing agents on dentin permeability and dentin tubule occlusion. J Adhes Dent 2002;4(3):211-21.

[23] Munksgaard EC. Amine-induced polymerization of aqueous HEMA/aldehyde during action as a dentin bonding agent. J Dent Res 1990;69(6):1236-9.

[24] Dos Santos PA, Garcia PPNS, Palma-Dibb RG. Shear bond strength of adhesive systems to enamel and dentin: thermocycling influence. J Mater Sci Mater Med 2005;16(8):727-32.

[25] Feitosa VP, Sauro S, Ogliari FA, Stansbury JW, Carpenter GH, Watson TF, et al. The role of spacer carbon chain in acidic functional monomers on the physicochemical properties of self-etch dental adhesives. J Dent 2014;42(5):565-74.

[26] Malacarne-Zanon J, Andrade e Silva SM, Wang L, de Goes MF, Martins AL, Narvaes-Romani EO, et al. Permeability of dental adhesives-a SEM assessment. Eur J Dent 2010;4(4):429-39.

[27] Tay FR, Pashley DH, Hiraishi N, Imazato S, Rueggeberg FA, Salz U, et al. Tubular occlusion prevents water-treeing and through-and-through fluid movement in a single-bottle: one-step self-etch adhesive model. J Dent Res 2005;84(10):891-6.

[28] Maia FJN, Clemente CS, Oliveira TMBF, Lomonaco D, Oliveira TIS, Almeida MO, et al. Electrochemical and computational studies of phenolic antioxidants from cashew nut shell liquid. Electrochim Acta 2012;79:67-73.

[29] Ge X, Ye Q, Song L, Misra A, Spencer P. Synthesis and evaluation of novel siloxane-methacrylate monomers used as dentin adhesives. Dent Mater 2014;30(9):1073-87. 